\title{
Applying the Moisture Availability Index (NTDI) over Vegetated Land in Central Asia: Mongolian Steppe
}

\author{
Abdelmoneim A. Mohamed1, Reiji Kimura² \\ ${ }^{1}$ Discipline of Geography, School of Agricultural, Earth and Environmental Sciences, \\ University of KwaZulu-Natal, Pietermaritzburg, South Africa \\ ${ }^{2}$ Arid Land Research Center, Tottori University, Tottori, Japan \\ Email: Ahmeda1@ukzn.ac.za, ehamir97@hotmail.com
}

Received 7 August 2014; revised 29 September 2014; accepted 14 October 2014

Copyright (C) 2014 by authors and Scientific Research Publishing Inc.

This work is licensed under the Creative Commons Attribution International License (CC BY). http://creativecommons.org/licenses/by/4.0/

(c) () 0 pen Access

\section{Abstract}

The intensity of recent droughts and the uncertainty of moisture variability in the context of increasing temperatures and decreasing precipitation have affected the Mongolian grassland. Mongolia typifies the steppe terrain and semiarid to arid continental climate that extends across much of Central Asia. In semi-arid areas like Mongolian steppe, vegetation type and distribution are directly relate to the amount of water that plants can extract from the soil. An index for assessment of moisture availability ( $m_{a}$ : defined as the ratio of actual to reference evapotranspiration) was developed, namely NTDI [1]. NTDI (Normalized Day-Night Surface Temperature Difference Index) is defined as the ratio of the difference between the maximum daytime surface temperature and the minimum nighttime surface temperature, to the difference between the maximum and minimum surface temperatures estimated from meteorological data by applying energy balance equations. A verification study conducted at Liudaogou River Basin of the Loess Plateau, China, indicated the capability of NTDI to estimate $m_{a}$ accurately, $\left(R^{2}=0.97, p<0.001\right)$ [1]. In Bayan Unjuul, Mongolia, application of NTDI during the growing season showed a significant inverse exponential correlation with $m_{a}\left(R^{2}=0.86, p<0.001\right)$. This result indicates that the NTDI is potent to be used as a surrogate of moisture availability in steppe terrain of Central Asia.

\section{Keywords}

Drought, Mongolian Steppe, Central Asia, NTDI, Moisture Availability $\left(\boldsymbol{m}_{a}\right)$ 


\section{Introduction}

Recent widespread and intense droughts have become likely manifestations of large-scale climate change, including global warming. Droughts have become widespread in the Northern Hemisphere, including Asia, and particularly in Mongolia [2]-[5]. Climate, and climate change is very relevant to society in Mongolia. Changes in climate patterns such as prolonged drought can translate into degradation of pastureland and loss of livestock and have serious economic effects.

The increasing drought frequency in Mongolia in recent years has resulted in important effects on Mongolian grassland. These effects have been phytomass decreases below-average [6]-[9], and could seriously threaten the pastoral and nomadic lifestyle of much of the population of Mongolia [10]. However, in semi-arid areas like Mongolian steppe, vegetation type and distribution relate directly to the amount of water that plants can extract from the soil [11]; as Mongolia typifies the steppe terrain and semiarid to arid continental climate that extends across much of Central Asia [12] therefore, understanding the spatial and temporal variability of moisture patterns, is critically important for food security in Mongolia, and other regions of central Asia.

When insufficient soil water is available, a water-stress occurs. Plant under stress decreases its transpiration through closing stomata. This decrease in the canopy water flux can have an impact on leaf temperature. Plant temperature has been recognized as indicator of water availability to plants [13] [14] and of plant water stress occurring at the beginning of drought [15]-[17] developed an index of crop water status based on the difference between canopy temperature (measured by an infrared thermometer) and air temperature. [18] developed this index further into the crop water stress index (CWSI), which they defined as the value $1-m_{a}$, where $m_{a}$ (moisture availability) is the ratio of actual to potential evapotranspiration. A number of experimental studies have shown that the diurnal surface temperature range of soils is a useful indicator of soil moisture [19] [20]. Diurnal surface temperature range as an index for quantifying the surface wetness condition of vegetation was initially found to be affected with evapotranspiration [21]. [1] developed an index non-destructively describes surface wetness conditions such as $m_{a}$, the Normalized Day-Night Surface Temperature Difference Index (NTDI). The NTDI is defined as the ratio of the difference between both radiative the maximum daytime surface temperature and the minimum nighttime surface temperature, to the difference between the maximum and minimum surface temperatures estimated from meteorological data by applying energy balance equations. Their previous study demonstrated that NTDI could be used as a robust surrogate for $m_{a}$ over semiarid vegetated land in Loess Plateau-China.

This paper compares the NTDI index with moisture availability $\left(m_{a}\right)$ over Mongolian Steppe. The goal of this study is to validate the capability of NTDI for simulate the wetness metrics $\left(m_{a}\right)$ for Mongolian Steppe based on ground-meteorological data collected at Bayan Unjuul Drought Experiment (DREX) site.

\section{Data and Site Description}

Meteorological data were acquired at an experimental observation stations in Bayan Unjuul in northern Mongolia $\left(47^{\circ} 04^{\prime} \mathrm{N}, 105^{\circ} 95^{\prime} \mathrm{E}, 1200 \mathrm{~m}\right.$ elevation; Figure 1) from two growing season periods 2004 and 2005. Normally, the growing season in the study area extends from May to October. According to statistics for 1995 to 2005 from the Mongolian Institute of Meteorology and Hydrology, the average annual temperature at Bayan Unjuul is $0.1^{\circ} \mathrm{C}$ and the average annual rainfall is $163 \mathrm{~mm}$. Most rainfall occurs from May to August (124 mm). Soils at Bayan Unjuul are classified as Kastanozems. The soil texture is silty loam to sand. Field capacity and permanent wilting point were $19.9 \%$ and $4.7 \%$, respectively. This region is located in the dry steppe zone that is characterized not only by a grass dominance, (e.g. Stipa krylovii and Agropyron cristatum), but also by shrub species (e.g. Caragana microphylla, and Artemisia adamsii) [22].

\section{Weather and Ground Observation Systems}

The weather observation system comprises two sub systems; Automatic Weather Station (AWS) and Automatic Ground-observing Station (AGS).

\subsubsection{Automatic Weather Station (AWS)}

AWS was set up on 21st June, 2004 at the center of the fenced area $(300 \mathrm{~m} \times 300 \mathrm{~m})$.The AWS had a data 


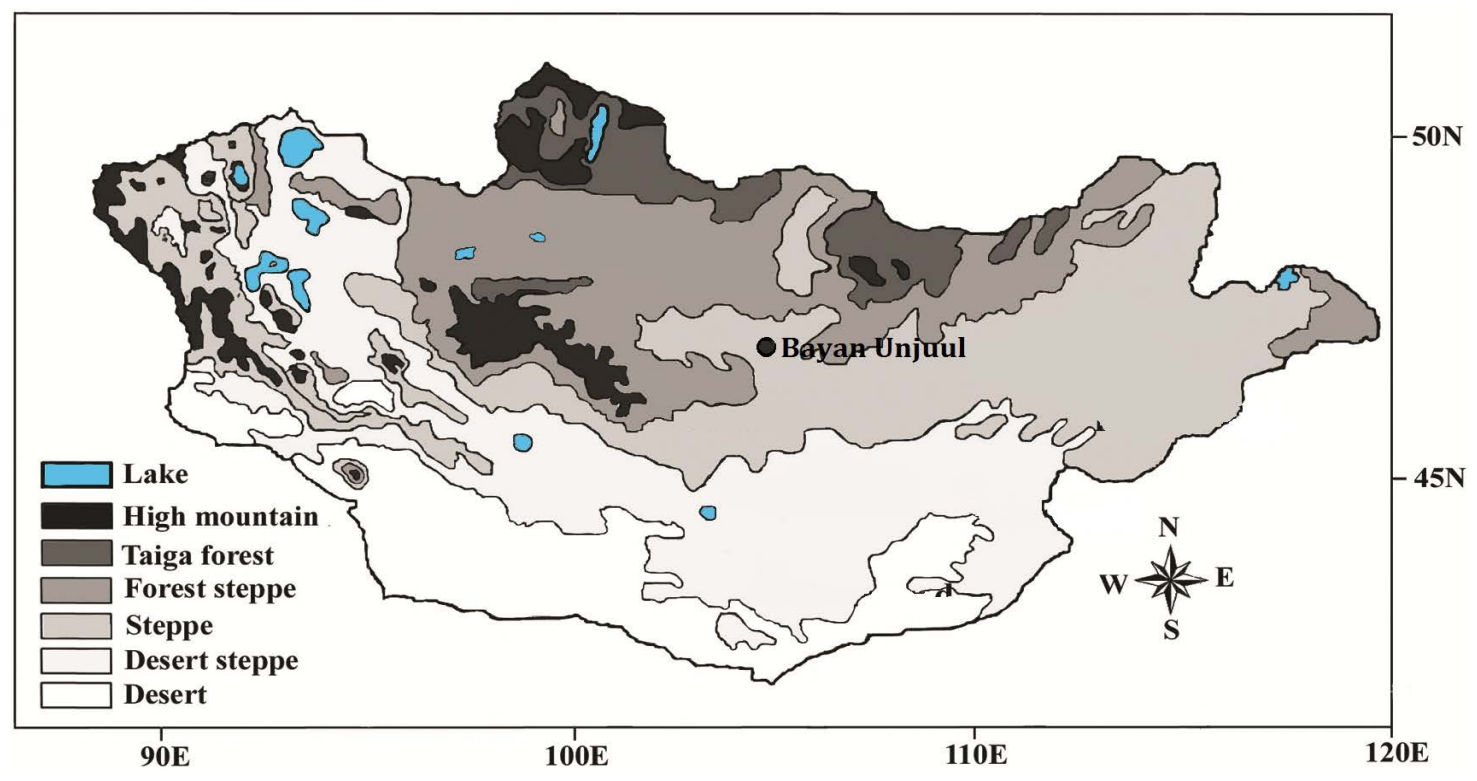

Figure 1. Map of mongolian natural vegetation zones and the experimental site at Bayan Unjuul (solid circle).

logger (CR23X, Campbell, USA) and sensors measuring aboveground physical quantities. To acquire sensible heat and latent heat fluxes using the eddy correlation methods, fluctuations in three-directional wind speeds, sonic virtual temperature and water vapor at $1.5 \mathrm{~m}$ above the ground were measured with a three-dimensional ultrasonic anemometer-thermometer (81,000, Young, USA) and an open-path krypton hygrometer (KH20, Campbell, USA). These two sensors were mounted side by side with a $12 \mathrm{~cm}$ separation between the KH20's optical path and the center of the 81,000 probe. Shortwave, longwave and photosynthetically active radiation (PAR) from the sky and the land surface, respectively, were independently measured with a net-radiometer which has four separate radiometers (CNR1, Kipp and Zonen, Holland) and two quantum sensors (LI190SZ, LI-COR, USA) at the $1.5 \mathrm{~m}$ height. Air temperature and relative humidity were measured with a temperature and relative humidity probe (HMP45A, Vaisala, Finland) at the $1.5 \mathrm{~m}$ height. Precipitation was measured with a tipping bucket rain gauge $(52,203, \mathrm{R}$. M. Young, USA) at the $1.5 \mathrm{~m}$ height. Wind speed and direction at the 1.8 $\mathrm{m}$ height were measured with three-cup anemometer and potentiometer (010C and 020C, respectively, Met One, USA). Air pressure at the $0.8 \mathrm{~m}$ height was measured with a pressure sensor (PTB210, Vaisala, Finland). The fluctuations of wind speeds, virtual temperature and water vapor were sampled by $10 \mathrm{~Hz}$ and the other data of AWS were sampled every $1 \mathrm{~s}$ and the 30-min mean values or the other statistics were logged on the data logger. The further information about the AGS instruments and observing system is available from [23].

\subsubsection{Automatic Ground-Observing Station (AGS)}

AGS was set up on 8th October, 2003. The AGS had a data logger (CR10X, Campbell, USA) and sensors measuring below-ground physical quantities. Soil water contents and ground heat fluxes at the $0.1 \mathrm{~m}$ and $0.3 \mathrm{~m}$ depth were measured with time domain reflectometry (TDR) sensors (TRIME-EZ, IMKO, Germany) and soil heat flux plates (HFT3.1, REBS, USA), respectively. Soil temperatures at every $0.05 \mathrm{~m}$ interval from the surface to the $0.95 \mathrm{~m}$ depth were measured with a thermocouple profiler (CHF-GP1, Climatec, Japan). The TDRs and the other sensors of AGS were sampled every 10 minutes and 10 seconds, respectively. The 30-min mean data were logged on the data logger. The further information about the AGS instruments and observing is available from [23].

Finally, all data acquired from both AWS and AGS were then averaged over 1-hour intervals using a FORTRAN program created by authors.

\section{Methods}

\subsection{NTDI Index}

[1] defined the Normalized Day-Night Surface Temperature Difference Index (NTDI) as follows: 


$$
\mathrm{NTDI}=\frac{T_{s(\text { day })}-T_{s(\text { night })}}{T_{\text {ssim(day })}-T_{\text {ssim(night })}}
$$

where $T_{s(\text { day) }}$ and $T_{s \text { (night) }}$ were the observed maximum and minimum surface temperature in the daytime, and nighttime, respectively. $T_{\text {ssim(day) }}$ and $T_{\text {ssim(night) }}$ are the daytime maximum and nighttime minimum surface temperatures, respectively, for a reference crop [24] estimated by using energy balance equations and meteorological data. $T_{\text {ssim }}$ is the hypothetical estimated surface temperature (when the ET=0), so $T_{\text {ssim(day) }}-T_{\text {ssim(night) }}$ represents the hypothetical maximum diurnal range of surface temperature (when the $\mathrm{ET}=0$ ). If the measured daily range of surface temperature is close to the simulated one, then conditions are dry, otherwise conditions are wet.

The observed maximum surface temperature in the daytime and the minimum surface temperature in the nighttime can be derived from the long-wave radiation data as follows:

$$
T_{s(\text { day or night })}=\left\{\left(L^{\uparrow}-(1-\varepsilon) L^{\downarrow}\right) / \varepsilon \sigma\right\}^{0.25}
$$

where $L^{\uparrow}$ is the upward long-wave radiation $\left(\mathrm{Wm}^{-2}\right), \varepsilon$ is the surface emissivity, $L^{\downarrow}$ is the downward long-wave radiation $\left(\mathrm{Wm}^{-2}\right)$, and $\sigma$ is the Stefan-Boltzmann constant $\left(5.67 \times 10^{-8} \mathrm{Wm}^{-2} \cdot \mathrm{K}^{-4}\right)$. Surface emissivity, representing the efficiency of emitting energy, was set to be 0.98 since vegetation emissivity values typically range between 0.97 and 0.99 [25].

In the simulation of daytime and nighttime surface temperatures, we applied the land surface heat balance equations and the observed meteorological data in each calculation. The land surface heat balance equations are as follows:

$$
R^{\downarrow}-G=\sigma T_{s}^{4}+H+\lambda E
$$

where

$$
R^{\downarrow}=(1-\text { ref }) S^{\downarrow}+L^{\downarrow}
$$

Here, $R^{\downarrow}$ is the total incident radiation $\left(\mathrm{Wm}^{-2}\right), G$ is the soil heat flux $\left(\mathrm{Wm}^{-2}\right), H$ is the sensible heat flux $\left(\mathrm{Wm}^{-2}\right), \lambda E$ is the latent heat flux $\left(\mathrm{Wm}^{-2}\right)$, ref is surface albedo, and $S^{\downarrow}$ is the global solar radiation $\left(\mathrm{Wm}^{-2}\right)$.

Using bulk transfer equations, the fluxes $H$ and $\lambda E$ can be written as follows:

$$
H=c_{p} \rho C_{H} U\left(T_{s}-T\right)
$$

and

$$
\lambda E=\lambda \rho C_{H} U \beta\left\{q_{\text {sat }}\left(T_{\mathrm{s}}\right)-q\right\}
$$

where $c p$ is the specific heat of air $\left(\mathrm{J} \cdot \mathrm{kg}^{-1} \cdot \mathrm{K}^{-1}\right), \rho$ is the air density $\left(\mathrm{kg} \cdot \mathrm{m}^{-3}\right), C_{H}$ is the bulk transfer coefficient, $U$ is the wind speed at the observation height $\left(\mathrm{m} \cdot \mathrm{s}^{-1}\right), T_{s}$ is the surface temperature $\left({ }^{\circ} \mathrm{C}\right), T$ is air temperature $\left({ }^{\circ} \mathrm{C}\right), \lambda$ is the latent heat of vaporization $\left(\mathrm{J} \cdot \mathrm{kg}^{-1}\right)$, and $\beta$ is the evapotranspiration efficiency (which has a value of one under completely wet conditions and a value of zero under extremely dry conditions). In this study, $\beta$ was set to be zero for both the daytime and nighttime surface temperature simulation, when $\beta$ set to zero, the LE is equal zero, and for the energy balance equation to be balanced the decrease in latent heat should lead to increase in sensible heat which results in high surface temperature, which is an as indicator of low moisture availability. $\quad q_{\text {sat }}\left(T_{s}\right)$ is the specific humidity at saturation at $T_{s}\left(\mathrm{~kg} \cdot \mathrm{kg}^{-1}\right)$, and $q$ is the specific humidity $\left(\mathrm{kg} \cdot \mathrm{kg}^{-1}\right)$. If the vegetation canopy and the land surface are assumed to be a single plane, $T_{s}$ can be expressed in an alternative form by substitution of Equations (5) and (6) into Equation (3), yielding a nonlinear equation for $T_{s}$ as follows:

$$
R^{\downarrow}-G-\sigma T_{s}^{4}-c_{p} \rho C_{H} U\left(T_{s}-T\right)-\lambda \rho C_{H} \beta\left\{q_{\text {sat }}\left(T_{\mathrm{s}}\right)-q\right\}=0
$$

The solution of Equation (7) for $T_{s}$ can be found by an iterative process

The soil heat flux $(G)$ [24] has the form:

$$
G=0.1 \times R_{n} \quad \text { (daytime) }
$$




$$
G=0.5 \times R_{n} \quad \text { (nighttime) }
$$

where

$$
R_{n}=(1-\text { ref }) S^{\downarrow}+L^{\downarrow}-\sigma T_{s}^{4}
$$

Here, $R_{n}$ is net radiation $\left(\mathrm{Wm}^{-2}\right)$.

The estimated surface temperature calculation takes into account the atmospheric stability, represented by Richardson number $\left(R_{i}\right)$, is used as the index to determine the atmospheric stability. The Richardson number is given by:

$$
R_{i}=\left[g\left(T_{\mathrm{s}}-T\right)(z-d)\right] / T U^{2}
$$

where $g$ is the acceleration due to gravity $\left(\mathrm{m} \cdot \mathrm{s}^{-2}\right), \mathrm{z}$ is the observational height $(2 \mathrm{~m}), d$ is the zero-plane displacement height $(\mathrm{m})$, which was determined by the following equation

$$
d=2 / 3 H_{c}
$$

where $H_{c}$ is the plant height of the reference crop $(=0.12 \mathrm{~m})$. Calculations considered the neutral conditions $\left(-0.05<R_{i}<0.05\right)$ (Figure 2).

\subsection{Calculation of Evapotranspiration and Moisture Availability}

The sensible heat flux $H$ and latent heat flux LE, which are elements of heat budget, were calculated using by the eddy covariance method. The data processing had six steps [23]:

1) Field observations to acquire covariance data; 2) Calibration to remove data biases; 3) Quality control to select good condition data; 4) Gap filling of $H$ to obtain daily value of $H$; 5) Estimation of daily LE as residual from the heat budget equation; and 6) Complement to energy imbalance for $H$ and LE to satisfy the energy budget equation

The conversion formula to convert latent heat LE to evapotranspiration per day is:

$$
\mathrm{LE} /\left(205 \times 10^{6} \times 86400\right)
$$

86,400 are seconds in a day.

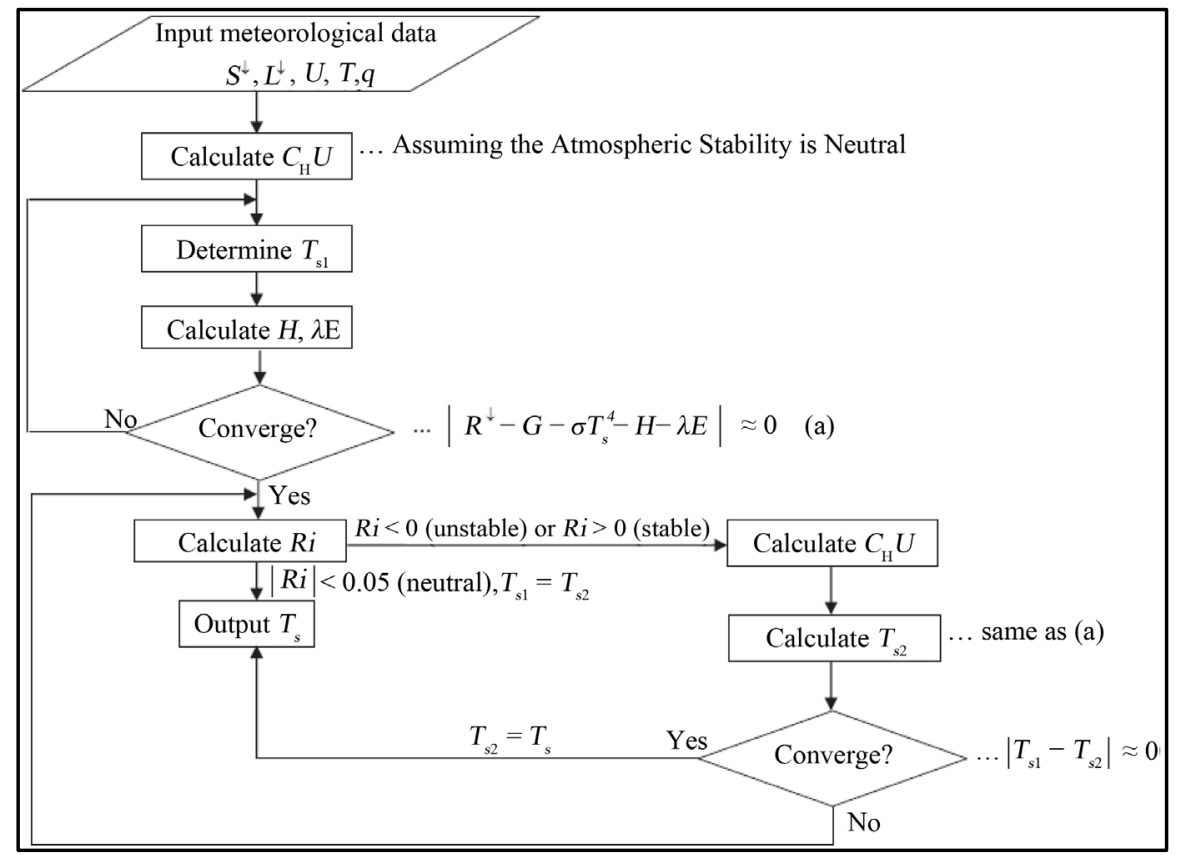

Figure 2. Flowchart for simulation of daytime and nighttime surface temperatures (after, Mohamed et al., 2011). 
We defined the moisture availability $m_{a}$ as follows:

$$
m_{a}=\frac{\mathrm{ET}}{\mathrm{ET}_{0}}
$$

where $\mathrm{ET} \mathrm{mm} \cdot \mathrm{day}^{-1}$ is the observed evapotranspiration by eddy covariance method and $\mathrm{ET}_{0}$ the reference crop ET $\left(\mathrm{ET}_{0} ; \mathrm{mm}^{-1 a y}{ }^{-1}\right)$ that can be obtained through the Penman-Monteith equation for a hypothetical reference crop [24]:

$$
\mathrm{ET}_{0}=\frac{0.408 \Delta\left(R_{n}-G\right)+\gamma \frac{900}{T+273} U_{2}\left(e_{s}-e\right)}{\Delta+\gamma\left(1+0.34 U_{2}\right)}
$$

Here, $U_{2}$ is the wind speed at $2 \mathrm{~m}$ height $\left(\mathrm{ms}^{-1}\right), e_{s}$ is the saturation vapour pressure $(\mathrm{kPa}), e$ the actual vapour pressure $(\mathrm{kPa}), \Delta$ the slope of the saturation vapour pressure curve at air temperature $\left(\mathrm{kPa} \cdot{ }^{\circ} \mathrm{C}^{-1}\right)$, and $\gamma$ the psychrometric constant $\left(\mathrm{kPa} \cdot{ }^{\circ} \mathrm{C}^{-1}\right)$. On a daily basis the mean of $G$ is small compared to $R_{n}$ and may often be ignored and assumed as zero [24].

\subsection{Results and Discussion}

Variation of NTDI, latent heat (LE) and sensible heat $(H)$ in Bayan Unjuul are shown in Figure 3. We selected typical non-cloudy days (22 days) during the growing season of two years 2004 and 2005 for calculation of these parameters. In the development of NTDI the high values represent the dry conditions while low values indicate wet condition. If the measured daily range of surface temperature is close to the simulated one, then conditions are dry, whereas the reverse indicates wet condition. Vegetation experiencing moisture stress, the transpiration rate decreases as the stomata close to minimize water loss, resulting in decreased latent heat flux. At the same time, owing to the requirement that the energy flux must balance, the sensible heat flux increased leading to an increased leaf temperature [15] and diurnal surface temperature range. The trend of NTDI is the inverse of the increasing of trends of LE which, indicate wet condition. The lowest value of NTDI was 0.75 (Day 18/8/2004) corresponding latent heat value of this day was $\left(99.6 \mathrm{Wm}^{-2}\right)$ although the most highly value of LE was observed on 6/8/2005, we can attribute this contrary in response of LE to the lowest NTDI index value as, Day 2004/08/17 experienced relatively one of the heaviest precipitation event recorded during the two growing seasons under analysis $(5.1 \mathrm{~mm})$ and in addition a precipitation event of $0.1 \mathrm{~mm}$ occurred in the Day 2004/08/18 itself. A precipitation event happened in DAY 2005/08/06 with $2 \mathrm{~mm}$ in amount. Apparently this amount of rainfall is remarkably less than that in Day 2004/08/17. In brief, LE is sensitive to precipitation events and we did not find any time lag between these two parameters in daily basis.

Figure 4 illustrates the seasonal variations in daily NTDI and the daily $m_{a}$. Daily NTDI ranged from 0.75 to 1.4. Moisture availability $m_{a}$ was nearly zero in half numbers of days selected in year 2005, but an abrupt increase occurred subsequently in response to that in LE. It is apparent that $m_{a}$ varied seasonally and with precipitation cycle (Figure 5). These findings agree with [1] [26] who stated that $m_{a}$ is sensitive to precipitation

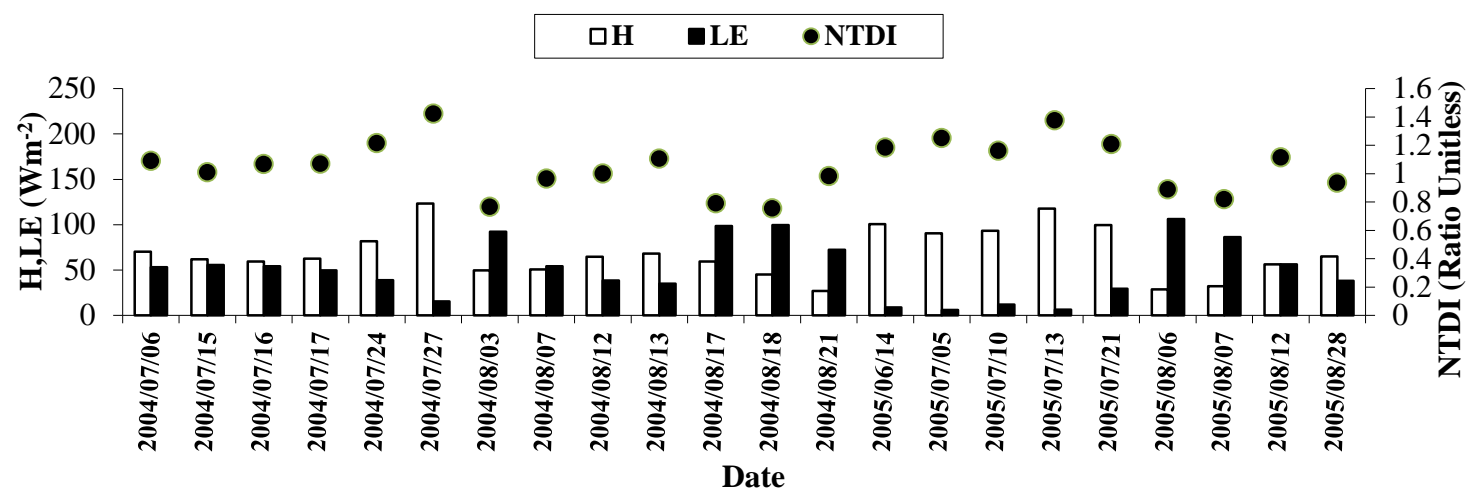

Figure 3. Temporal patterns of energy fluxes of two years 2004, 2005 growing seasons observed in 22 non-cloud days including sensible heat $(H)$, latent heat (LE) and NTDI calculated for the same period. 


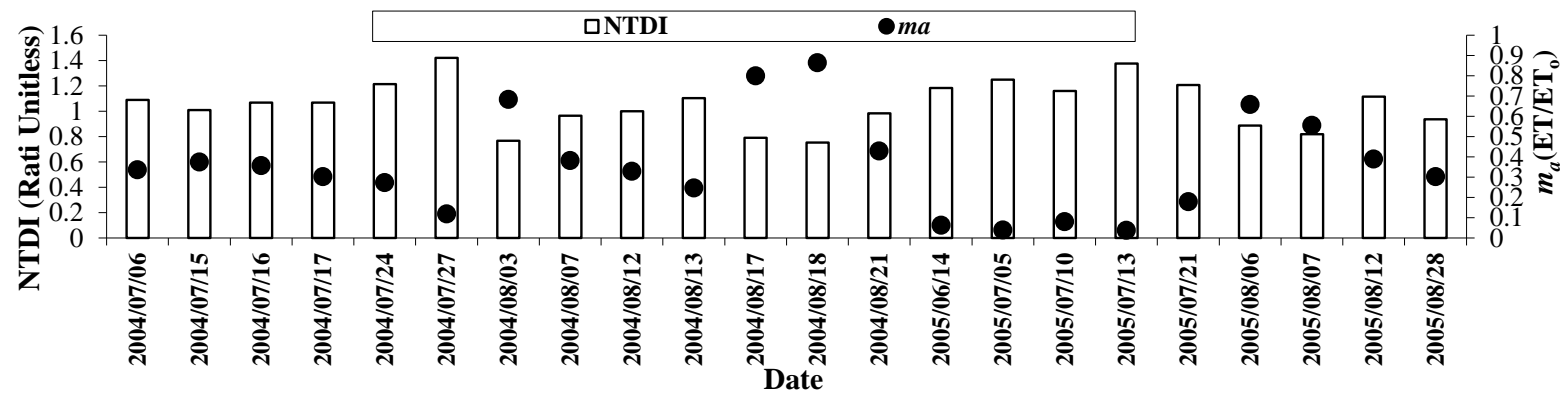

Figure 4. Temporal dynamics of the NTDI (open bars) and the moisture availability $\left(m_{a}\right)$ (solid circles) calculated for 22 non-cloud days of the two years 2004, 2005 growing season.

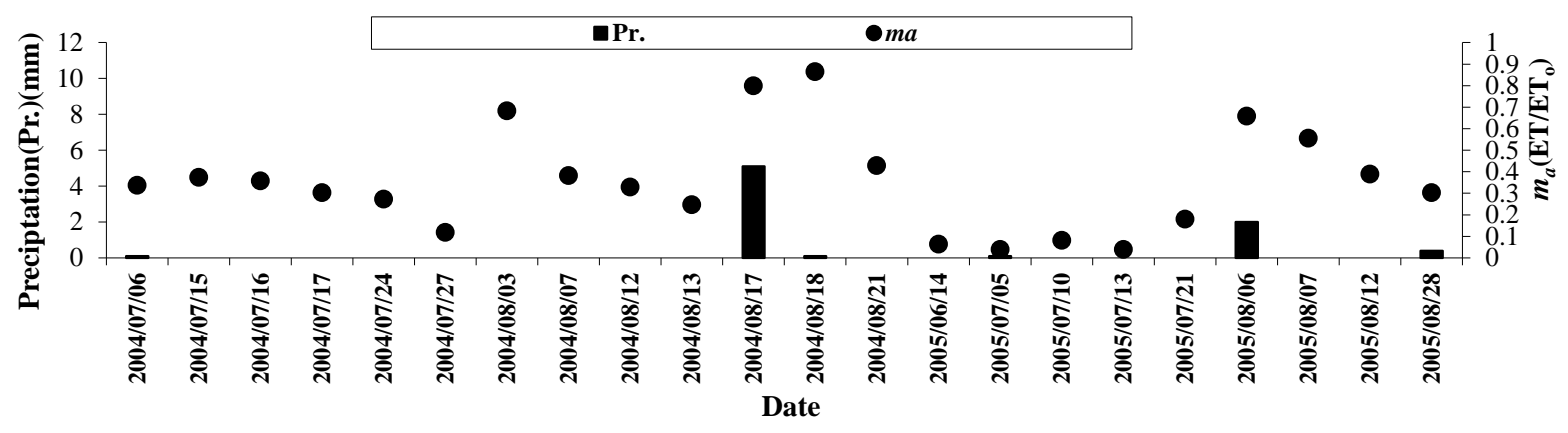

Figure 5. Temporal dynamics of the precipitation (Pr.) (solid bars) and the moisture availability $\left(m_{a}\right)$ (solid circles) calculated for 22 non-cloud days of the two years 2004, 2005 growing season.

events. $\quad m_{a}$ like LE has inverse relationship to NTDI. The largest $m_{a}$ value (0.86), as it corresponded to the lowest NTDI value (0.75), and the lowest $m_{a}$ value (0.038) corresponded to the highest NTDI index value (1.4), these result assure the solid physical base for the development of the NTDI Index which is crucial to approve the generality of the index over different environments to be used as an indication of environment wetness status.

Relationship of NTDI for 22 clear sky days to moisture availability $\left(m_{a}\right)$ is shown in Figure 6 . We selected typical, non-cloudy days (22 days) during the two growing season for calculation of these parameters. The NTDI showed a strong correlation with $m_{a}\left(R^{2}=0.86 ; p<0.0001\right)$, and it can be explained in terms of the definition of $m_{a}$ as the ratio between the observed ET and $\mathrm{ET}_{0}$. ET is affected by both meteorological and biophysical conditions, whereas $\mathrm{ET}_{0}$ is an index of meteorological demand, which means that $m_{a}$, like the NTDI, is a biophysical parameter (Equation (1)). Thus, the normalizing procedure in the calculation of the NTDI removes the meteorological influences so that the NTDI represents biophysical conditions only [1]. Our findings agree with the result of a verification study conducted at grasslands in the Loess Plateau, China where the NTDI was developed and they also explain why $m_{a}$ is highly related to NTDI.

\section{Concluding Remarks}

Reduced water availability triggers the onset of an agricultural drought, heightening the demand for an accurate, timely method of quantifying the wetness of a vegetated surface.

Mongolia typifies the steppe terrain and semiarid to arid continental climate that extends across much of Central Asia. In semi-arid areas like Mongolian steppe, vegetation type and distribution relate directly to the amount of water that plants can extract from the soil, therefore, understanding the spatial and temporal variability of moisture patterns, is critically important for food security in Mongolia, and other regions of central Asia. We validated a new index, the NTDI, which developed by [1] with observations from a grassland of Mongolian Steppe. We showed that the NTDI has a strikingly high correlation with $m_{a}\left(R^{2}=0.86 ; p<0.0001\right)$.

The results of comparing NTDI with the energy budget metrics (e.g., $H$ and LE,) are consistence with the theory behind the development of the Index which is necessary to approve the generality of the index over dif- 


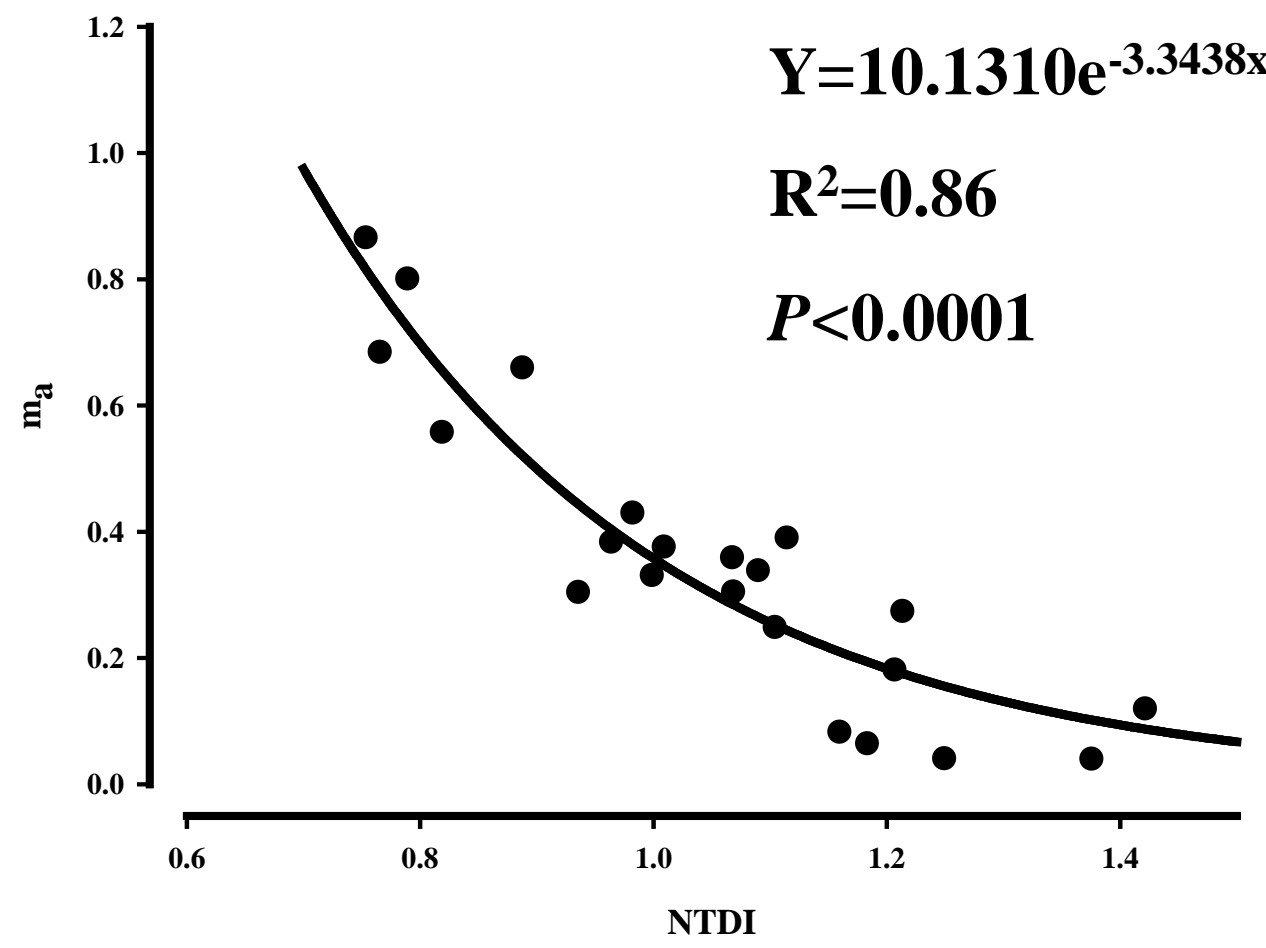

Figure 6. Relationship between the NTDI and moisture availability $\left(m_{a}=\mathrm{ET} / \mathrm{ET}_{0}\right)$.

ferent environments. Nevertheless, further studies are necessary to expand this method for other regions. The NTDI should be tested for it suitability in different climate conditions and for spatial application. The calibration of remotely sensed parameters (e.g., The MODIS sensor offers almost daily land surface temperature (LST) data) needs to be identified.

There are some limitations to the use of the NTDI. Some meteorological data required for the NTDI calculation (such as solar radiation) are not always available at many meteorological stations. Another problem is that the calculation procedure can be used only on clear sky days. To apply this index on an annual or interannual basis, a method of interpolation between clear and non-clear days must be developed.

\section{Acknowledgements}

This research was supported by the Global COE Program and KAKENHI Grant No. 20405038 of the Japan Ministry of Education, Culture, Sports, Science and Technology.

\section{References}

[1] Mohamed. A.A., Kimura, R., Shinoda, M. and Moriyama, M. (2011) Diurnal Surface Temperature Difference Index Derived from Ground-Based Meteorological Measurements for Assessment of Moisture Availability. Journal of Arid Environments, 75, 156-163. http://dx.doi.org/10.1016/j.jaridenv.2010.09.013

[2] Barlow, M., Cullen, H. and Lyon, B. (2002) Drought in Central and Southwest Asia: LaNiña, the Warm Pool, and Indian Ocean Precipitation. Journal of Climate, 15, 697-700.

http://dx.doi.org/10.1175/1520-0442(2002)015<0697:DICASA>2.0.CO;2

[3] Dai, A., Trenberth, K. and Karl, T. (1998) Global Variations in Droughts and Wet Spells: 1900-1995. Geophysical Research Letters, 25, 3367-3370. http://dx.doi.org/10.1029/98GL02389

[4] Hoerling, M. and Kumar, A. (2003) The Perfect Ocean for Drought. Science, 299, 691-694. http://dx.doi.org/10.1126/science.1079053

[5] Lotsch, A., Friedl, M.A., Anderson, B.T. and Tucker, C.J. (2005) Response of Terrestrial Ecosystems to Recent Northern Hemispheric Drought. Geophysical Research Letters, 32, Article ID: L06705.

http://dx.doi.org/10.1029/2004GL022043 
[6] Erdenetsetseg, D., Shinoda, M. and Nemoto, M. (2004) Drought Assessment in Mongolia. Proceedings of International Conference on High-Impact Weather and Climate: Understanding, Prediction and Socio-Economic Consequences. Seoul, 22-24 March 2004, 288-291.

[7] Miyazaki, S., Yasunari, T., Miyamoto, T., Kaihotsu, I., Davaa, G., Oyunbaatar, D., Natsagdorj, L. and Oki, T. (2004) Agrometeorological Conditions of Grassland Vegetation in Central Mongolia and Their Impact for Leaf Area Growth. Journal of Geophysical Research, 109, Article ID: D22106. http://dx.doi.org/10.1029/2004JD005179

[8] Munkhtsetseg, E., Kimura, R., Wang, J. and Shinoda, M. (2007) Pasture Yield Response to Precipitation and High Temperature in Mongolia. Journal of Arid Environments, 70, 94-110. http://dx.doi.org/10.1016/j.jaridenv.2006.11.013

[9] Zhang, Y., Munkhtsetseg, E., Kadota, T. and Ohata, T. (2005) An Observational Study of Ecohydrology of a Sparse Grassland at the Edge of the Eurasian Cryosphere in Mongolia. Journal of Geophysical Research, 110, Article ID: D14103.

[10] Davi, N.K., Jacoby, G.C., D’Arrigo, R.D., Baatarbileg, N., Li, J.B. and Curtis, A.E. (2009) A Tree-Ring-Based Drought Index Reconstruction for Far-Western Mongolia. International Journal of Climatology, 29, 1508-1514. http://dx.doi.org/10.1002/joc.1798

[11] Millennium Ecosystem Assessment (2005) Ecosystems and Human Well-Being. World Resources Institute, Washington DC.

[12] Zhang, J. and Lin, Z. (1992) Climate of China. John Wiley \& Sons, New York, and Shanghai Scientific and Technical Publishers, Shanghai, 376 p.

[13] Gates, D.M. (1964) Leaf Temperature and Transpiration. Agronomy Journal, 56, 273-277. http://dx.doi.org/10.2134/agronj1964.00021962005600030007x

[14] Wiegand, C.L. and Namken, L.N. (1966) Influences of Plant Moisture Stress, Solar Radiation and Air Temperature on Cotton Leaf Temperature. Agronomy Journal, 58, 582-586. http://dx.doi.org/10.2134/agronj1966.00021962005800060009x

[15] McVicar, T.R. and Jupp, D.L.B. (1998) The Current and Potential Operational Uses of Remote Sensing to Aid Decisions on Drought Exceptional Circumstances in Australia: A Review. Agricultural Systems, 57, 399-468. http://dx.doi.org/10.1016/S0308-521X(98)00026-2

[16] Idso, S.B., Jackson, R.D. and Reginato, R.J. (1977) Remote-Sensing of Crop Yields. Science, 196, 19-25. http://dx.doi.org/10.1126/science.196.4285.19

[17] Jackson, R., Reginato, R. and Idso, S. (1977) Wheat Canopy Temperature: A Practical Tool for Evaluating Water Requirements. Water Resources Research, 13, 651-656. http://dx.doi.org/10.1029/WR013i003p00651

[18] Jackson, R.D., Idso, S.B., Reginato, R.J. and Pinter Jr., P.J. (1981) Canopy Temperature as a Crop Water Stress Indicator. Water Resources Research, 17, 1133-1138. http://dx.doi.org/10.1029/WR017i004p01133

[19] Price, J.C. (1982) Estimation of Regional Scale Evapotranspiration through Analysis of Satellite Thermal-Infrared Data. IEEE Geoscience and Remote Sensing, 20, 286-292. http://dx.doi.org/10.1109/TGRS.1982.350445

[20] Van de Griend, A.A., Camillo, P.J. and Gurney, R.J. (1985) Discrimination of Soil Physical Parameters, Thermal Inertia and Soil Moisture from Diurnal Surface Temperature Fluctuations. Water Resources Research, 21, 997-1009. http://dx.doi.org/10.1029/WR021i007p00997

[21] Price, J.C. (1985) On the Analysis of Thermal Infrared Imagery: The Limited Utility of Apparent Thermal Inertia. Remote Sensing of Environment, 18, 59-73. http://dx.doi.org/10.1016/0034-4257(85)90038-0

[22] Gunin, P.D., Vostokova, E.A., Dorofeyuk, N.I., Tarasov, P.I. and Black, C.C. (1999) Vegetation Dynamics of Mongolia. Kluwer Academic Publishers, Dordrecht, 240 p. http://dx.doi.org/10.1007/978-94-015-9143-0

[23] Nemoto, M. (2007) Impact of Snow and Vegetation Activity on Energy and Water Balance in a Mongolian Grassland. Dissertation, Tokyo Metropolitan University, Tokyo.

[24] Allen, R.G., Pereira, L.S., Raes, D. and Smith, M. (1998) Crop Evapotranspiration: Guidelines for Computing Crop Water Requirements-FAO Irrigation and Drainage Paper 56. FAO, Rome.

[25] Rosenberg, N.J. (1974) Microclimate: The Biological Environment. John Wiley \& Sons, Inc., New York, 495 p.

[26] Gillies, R.R. and Carlson, T.N. (1995) Thermal Remote Sensing of Surface Soil Water Content with Partial Vegetation Cover for Incorporation into Climate Models. Journal of Applied Meteorology and Climatology, 34, 745-756. http://dx.doi.org/10.1175/1520-0450(1995)034<0745:TRSOSS>2.0.CO;2 
Scientific Research Publishing (SCIRP) is one of the largest Open Access journal publishers. It is currently publishing more than 200 open access, online, peer-reviewed journals covering a wide range of academic disciplines. SCIRP serves the worldwide academic communities and contributes to the progress and application of science with its publication.

Other selected journals from SCIRP are listed as below. Submit your manuscript to us via either submit@scirp.org or Online Submission Portal.
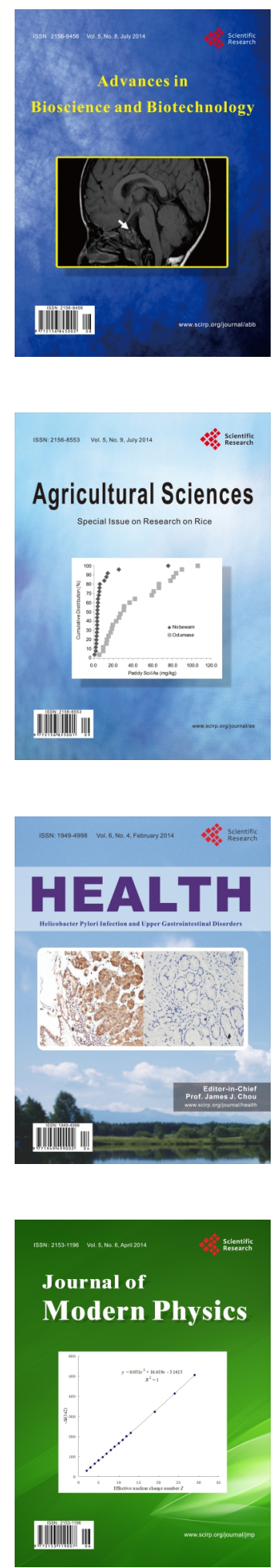
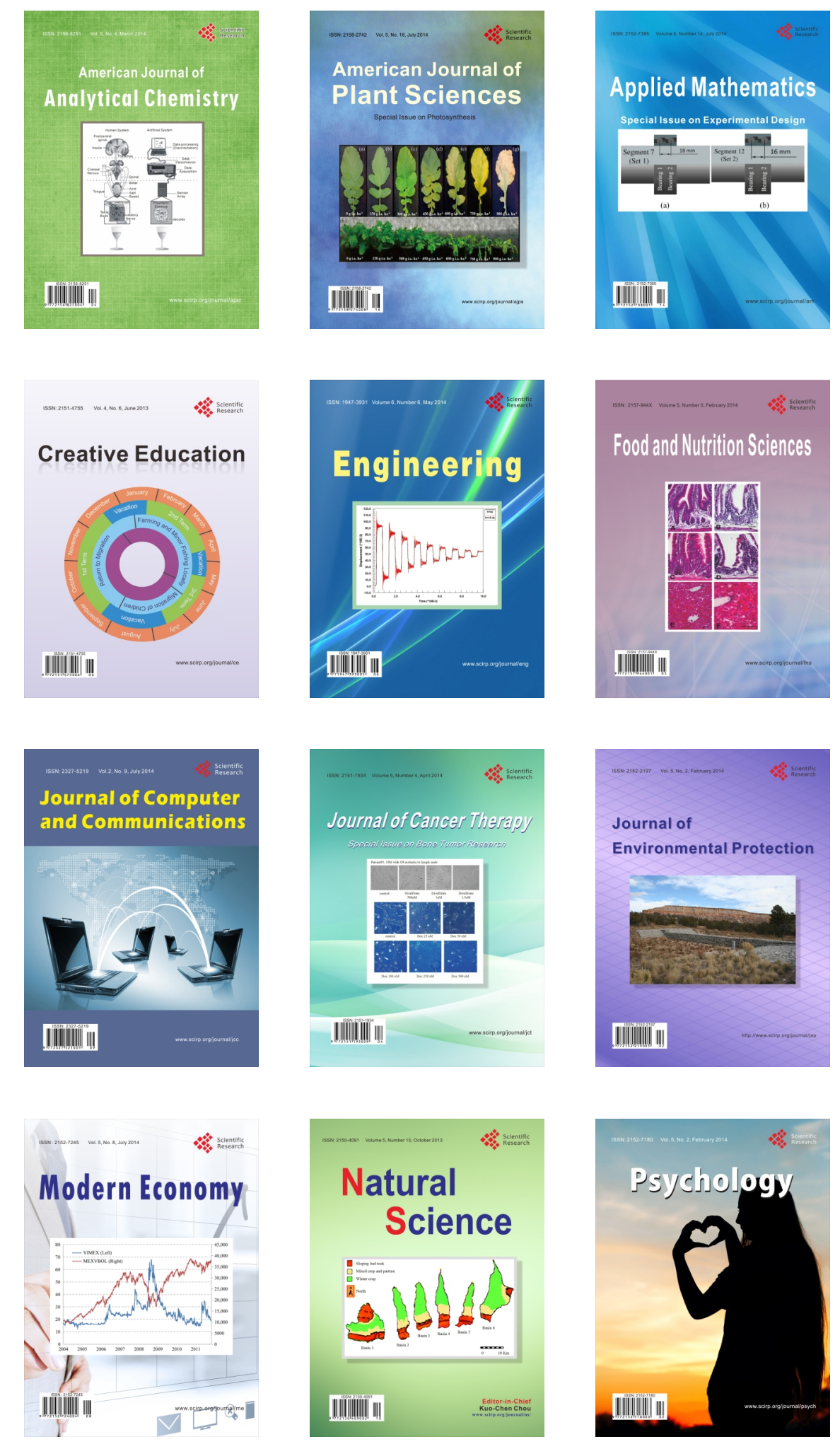